\title{
Editorial
}

\section{Mind the Gap!}

\section{The Challenge of Widening Social Cleavages}

Tolerance, rather than a virtue that animates rational debate and understandings of difference, has become a codified instrument of government constructing opposition. Tolerance is seen as a gesture towards inclusion, something that the so called majority 'put up with', within certain limits towards people different from themselves the poor, older people, refugees, people with disability, gay men and lesbians, indigenous Australians and migrants from 'non-western' backgrounds. Tolerance has significant cultural, social and political effects that go beyond the surface operations of reducing conflict or protecting the marginalised. In contrast social inclusion should produce an imperative to examine aspects of social organisation that rank different characteristics of being human, resulting in acceptance of unequal differential treatment. There are increasing demands for walled existences under the veneer of security the "promise of security via social conformity and distance from unsettling cultural and socioeconomic differences" (Gleeson, 2005), to a kind of homosociality of sameness and assumed certainty. It's time to reassess building nation beyond the residual approach of handouts to the excluded. Nation building requires the establishment of civil and legal institutions as well as a political culture beyond the squabbles of a partisan politics that celebrates diversity within which some sort of collective vision of national destiny might be cultivated.

Long ago Jewish philosopher Martin Buber (1955) argued for a relational dialogue instead of the more common dominant approach of difference as an exception afterthought. At the heart of his philosophy is the idea of sacrificing the ego or the individual, to culturally dispense with a rampant self-sealed individualism so touted by marketing companies and contrived notions of productivity. For Buber (1955) dialogue, what he calls the 'I-Thou relationship' asks an individual to place his or her needs to the side while stepping into the other's shoes. This encounter, Buber (1955) 
argues is "where each of the participants really has in mind the other or others in their present and particular being and turns to them with the intention of establishing a living mutual relation between himself and them" (p. 19). Whilst this ethos is difficult to accomplish, the conscious act of a living mutual relation is not merely about coming to an agreement or completely uniting with the other, but rather embracing the difference. Social inclusion then is more than tolerance; it is a deepening awareness and a stance to live "self-consciousness[ly] through the processes of disciplined inquiry and understanding which characterize the act of relating dialogically to the world" (Hilliard, 1973, p. 105). In a different vein, Buddhist thought views suffering as a universal experience where there is an equality that reaches across the spectrum of all sentient beings. Whilst suffering can be 'individual' at the same time suffering can be conceived of as relational through the re-cognition of oneself in the pain of another. This is not to relativise the experiences because the conditions of suffering and their corresponding recognitions differ from circumstance to circumstance and between individuals. The Dhammapada (verse 10) expresses this cross referentiality: "All beings are afraid of pain, all beings are afraid of death. Recognising oneself in others, one should neither kill nor cause to kill." In Buddhism, all phenomena are dependently arisen (paticcca samuppada). As such, embodied existence is unstable, uncertain, tentative and conditional. Hence paticcca samuppada acts as Buddhism's primary ontological principle for the understanding of beingness which is inherently relational. Human culture and nationalism do not exist in isolation but rather flourish or diminish in relation and reaction. In the Australian context as 2012 comes to a close, we may wish to pause and consider how at an individual level, in the local and communally at the State or National level, we deal with embracing diversity. Do we circumscribe difference and consider the parameters (and limits) of inclusion on a case by case, piecemeal basis? Or do we anticipate diversity (as the Equality Act, 2010, UK) might propose and ask what do we (as people, planners, decision makers, communities) need to consider to make our environments truly welcoming, cognisant of, and responsive to differences?

In the real world - there is the NDIS (National Disability Insurance Scheme) to consider, endorsing a view that disability is not peripheral to social life but needs to be factored in as a core expenditure unit of government for ALL the people. Then 
there is the ongoing border wars and classification of people depending upon the kind of mode they arrive to Australia. In the 2009-10, it was estimated that approximately 15800 people overstayed their visa. The estimated number of people who have overstayed their visas and remain in Australia is about 53900 . (Department of Immigration \& Citizenship, 2012). Yet there is an obsessive focus on 'boat people', the reinscribed geographies of Australian detention centres or excluding the reunion of child refugee with their families. On 13 December, the High Court of Australia dismissed an application by an Afghan refugee Javed Tahiri, to appeal a decision by the Department of Immigration and Citizenship who rejected his application to bring his mother and four siblings to Australia. Tahiri was denied permission because the Department argued they need the permission of the father who has been missing for 10 years! At the State level, the newly elected LNP government of Campbell Newman in Queensland has overturned equality initiatives of the previous government in securing comparable entitlements to people in same sex relationships and families, creating an apartheid system of family law and Queensland became one of the few states to actively wind back human rights protections toward a particular minority group [1].

This issue of the Journal of Social Inclusion collectively is about bridging the gaps of societal exclusion and the unequal relations produced by widening social cleavages. In a timely manner a number of articles point to the possibility of electronic technologies being used to produce equalising opportunities. Charleston showcases the Australian Catholic University's Catalyst-Clemente program adopted to bridge the digital divide amongst university students from disadvantaged backgrounds. The article tells a story of growth from technological mystification towards an engagement with media technologies that harnessed skills and the self-confidence of students. This theme of technology networks is extended by Tendy, Wallis, Ghosh \& Howitt, who critically review the impact of Australia's roll out of the National Broadband Network (NBN) on local communities. The so-called digital divide between those who have access to digital services at reasonable levels of cost, speed and reliability and those who don't should be a matter of national significance. Economic and social implications for regions, nations and social groups without access are seen as significant. The article points to a digital divide between age groups, professions and social classes; the need for life-time training/education and 
impediments due to a lack of skills or the means to get online among people with disability, aged people, and children at risk and people with literacy concerns. The article by Goldingay concerns narrowing the gap for what she calls 'silver surfers'; those older people over 65 years using the internet for social networking. This Victorian study was restricted to White Australians from the Geelong area. The study provides valuable information around identify formations, contestations over the 'valuable' use of time and socio-economic factors that exclude older Australians from not only engaging in the usage of such technologies but also their feelings around the entitlement to access in the first place.

The final two articles in this issue, work around the theme of individualized responses to gaps in inclusions and dealing with the effects of exclusion in the day to day. Hutchinson \& Dorsett write of resilience and refugee people in particular composite themes in the literature. The article critically reviews the sometimes 'jingoistic' usage of resilience as a form of victim blaming western modality, to consider what this concept might mean for practice when perceived as a communal construction and relation. Hutchinson \& Dorsett provide a robust piece that moves away from resilience as behaviour poverty to one that is situated within the spectrum of anti-oppressive practice. Satisfaction with mental health services has an effect on service user wellbeing. Ojala \& Wheeler's in their valuable narrative study of five older Queensland mental health service users and their perceptions of freedom and independence whilst residing in a facility.

The Journal closes with two commentary pieces by Wills (about boys, education and New Zealand) and Butteriss on Australia's proposed National Disability Insurance Scheme.

We take this opportunity to thank all the reviewers of manuscript submissions this year, without your valuable input we would not be able to produce a quality journal.

\section{Fiona Kumari Campbell, Editorial Team}

Fiona is currently Deputy Head (Learning \& Teaching Scholarship) \& Chair, Legal Practice Centre, Griffith Law School, Griffith University. 
[1]. In May 2012, the QLD government decided to strip \$2.6 million in annual funding from the sole organisation in the state that focused on HIV/AIDS prevention and support for gays and lesbians. In July civil partnership legislation was downgraded to 'relationships registration'.

Buber, M. (1955). Dialogue: In between man and man. Boston: Beacon Press.

Department of Immigration \& Citizenship, (2012). Overstayers and other unlawful non-citizens (Australian Government Fact Sheet 86). Retrieved from http://www.immi.gov.au/media/fact-sheets/86overstayers-and-other-unlawfulnon-citizens.htm

Gleeson, B. (2005). What's driving suburban Australia? Fear in the tank, hope on the horizon (Griffith REVIEW Edition 2: Dreams of Land). Retrieved from http://griffithreview.com/edition-2-dreams-of-land/whats-driving-suburbanaustralia-fear-in-the-tank-hope-on-the-horizon

Hilliard, F. (1973). "A re-examination of Buber's address on education." British Journal of Educational Studies, 21(1), 40-49.

Remon, J. (1980). Self and non-self in early Buddhism. Netherlands: Mouton Publishers. 